pneumophila has been observed; inhalation infection in guinea-pigs required only about one two-hundredth as many organisms as intraperitoneal infection to produce a comparable febrile response. ${ }^{1}$

This clinically important feature of $L$ pneumophila might be explained, at least partly, by the unusually acid conditions which it requires for growth. The optimum $\mathrm{pH}$ for culture of $L$ pneumophila in vitro is $6 \cdot 6-6 \cdot 9 .^{2}$ As the $\mathrm{pH}$ is increased beyond 7 growth becomes poorer, until at about $7 \cdot 25$ it is either extremely sparse or does not occur. The $\mathrm{pH}$ of fertile hen's egg yolk sac, also used for the culture of $L$ pneumophila (and organisms such as rickettsias), is between 6.6 and 6.85 , depending on the age of the embryo.

Human subcutaneous tissue $\mathrm{pH}$ is similar to that of blood, about $7 \cdot 4$ at $37^{\circ} \mathrm{C}$. ${ }^{3}$ However, pulmonary tissue $\mathrm{pH}$ is much more acid at about $6 \cdot 7^{4}$-that is, the hydrogen ion concentration in the lung is about five times that in subcutaneous tissues and optimum for the growth of Legionella. If other extrapulmonary tissues have $\mathrm{pH}$ values similar to subcutaneous tissue, it is hardly surprising that $L$ pneumophila is primarily a pulmonary pathogen.

A similar argument might also apply to certain other micro-organisms which tend to infect by inhalation, such as Mycobacterium tuberculosis (optimum pH 6.5-6.8), Francisella tularensis ( $\mathrm{pH} 6 \cdot 8$ ), and other legionellas. Although the first two have optimal $\mathrm{pH}$ values similar to that of $L$ pneumophila, their ability to grow under more alkaline conditions might explain their greater capacity to cause extrapulmonary disease.

DAvid RUtTER

PHLS Centre for Applied Microbiology and Research, Microbiological Safety Reference Laboratory,

Porton Down

Salisbury, Wilts SP4 0JG

Berendt RF, Young HW, Allen

F Infect Dis $1980 ; 141$ :186-92.

${ }^{2}$ Rutter DA, Maber HB. Lancet 1979; i :723-4.

+ Effos RM, Chinard FP. F Clin Invest 1969;48:1983 96.

SIR,-Your leading article (2 August, p 339) rightly draws attention to the variable severity of legionnaires' disease, and prompts some comments.

Legionellosis covers an ambiguous clinical spectrum of illness ranging from mild selflimiting disease unassociated with pneumonia (for example, Pontiac fever) to multisystem illness including pneumonia associated with significant case fatality rates; a recent paper described also chronic aspects with pulmonary fibrosis. ${ }^{1}$ Despite the extraordinary expansion of knowledge in several aspects of legionnaires' disease, understanding of many pathophysiological reactions in man following legionellosis is still rudimentary, and virtually nothing is known about the factors responsible for disease production, particularly in the lungs.

In addition, the histopathological findings in lung tissue vary considerably and may be due also to secondary infections, the results of therapy, or underlying disease. ${ }^{2}$ The undoubted role of the host defences in determining mild or severe illness is more presumed than established; however, recent experimental observations have demonstrated that Legionella pneumophila can enter a type of human cell not specialised for phagocytosis (that is, the fibroblast), thrive intracellularly, and exert a cytopathic effect. ${ }^{3}$ The marked pulmonary pathology associated with fatal infections by this organism may be related to initial destruction of lung cells by a similar mechanism. Subsequent bacterial multiplication within inflammatory cells may account for the inflammatory cell necrosis often prominent in the histopathology of legionnaires' disease, and release of lysosomal enzymes from lysed cells may intensify the pulmonary damage. ${ }^{3}$ In other words, if bacteria are killed by the alveolar macrophage disease is averted, while replication of the invading organism within the phagocyte causes the host to be compromised. ${ }^{4}$ According to most recent data (presented by $\mathrm{M}$ A Horwitz and $\mathrm{S} C$ Silverstein recently at the 20th Interscience Conference on Antimicrobial Agents and Chemotherapy), Legionella pneumophila resists killing by human phagocytes, antibody, and complement.

Finally, you rightly state the relevance of knowledge of the biological characteristics of the causative organism. From this point of view, it is important to call attention to the "toxic" products of the bacterium as potential candidates in the pathogenetic mechanisms. Until now we have had few data on haemolytic, ${ }^{6}$ proteolytic, ${ }^{7}$ and cytotoxic activities, ${ }^{8}$ and more consistent observations regarding an endotoxic-like property, ${ }^{9}$ demonstrated also in legionella-like organisms. ${ }^{10}$

These summarised data are clearly preliminary and their interpretation is limited by the small number of experiments. More detailed study dealing with the biological profile of the bacterium will be necessary. However, despite these limitations, we believe that the findings are very encouraging for the understanding of what has been called the "fascinating yet horrible" organism.

Institute of Medical Microbiology,

Donato Fumarola University of Bari,

Baur X, Ruckdeschel G, Fruhmann G. Dtsch Med Wochenschr 1980;105:561-6.

Lattimer GL, Rachman RA, Scarlato M. Ann Clin Lab Sci 1979;9:353-61.

Wong MC, Ewing EP, Callaway CS, Peacock WL. Infect Immun 1980;28:1014-8.

Kishimoto RA, Kastello MD, White JD, et al. Infect Immun 1979;25:761-3.

Fumarola D. Br Med f 1979;ii:796.

Baine WB, Rasheed JK, Maca HW, Kaufmann AF. Rev Infect Dis 1979;1:912-7. 917.

${ }_{8}^{8}$ Friedman RL, Iglewski BH, Miller RD. Infect Immun 1980;29:271-4

1980;29:271-4. 1980;3:115-21.

Fumarola D, Miragliotta G, Munno I, Monno R.
IRCS Med Sci $1980 ; 8 \cdot 374$.

\section{A better system for polio vaccination in developing countries?}

SIR,-In a recent communication in your journal (23 August, p 542) the "cluster" or "pulse" immunisation studies employing trivalent vaccines even with 97.9-99.3\% loss in vaccine potency are reported to have yielded seroconversion rates of $74 \% ; 96 \%$, and $71 \%$ for types 1,2 , and 3 respectively. These results appear to match well with their earlier results with potent vaccines when used in sporadic manner. It has been presumed that the use of potent vaccines in a mass campaign within a very short span of time would enhance the low seroconversion rates observed so very frequently in warm areas. ${ }^{1}$

Strangely enough, the authors have not stressed the need of ensuring delivery in the mouth of each vaccinee of adequate numbers of live virus particles of each type. Certainly it has been customary to assess the live virus content of a trivalent vaccine in terms of the sum total of live virus particles of three types ${ }^{2}$; but such a practice seems to be very doubtful indeed, because a partial or even complete inactivation of one or two of three types will be compatible, on in vitro testing, with satisfactory and adequate total live virus content. Is it therefore not possible that all these low seroconversion rates for type 1 and 3, so far, have in reality been due to the grossly insufficient or even negligible quantum of the homotypic strain in the vaccine drops delivered in the individual's mouth?

The authors would also appear not to have considered the insults and tortures to which even a potent vaccine with an adequate quantum of each type can be subjected to at the final moment of its administration to an individual. Apart from the use of outdated vaccine with hardly enough live virus particles, exposure to sun for long hours, simultaneous ingestion of chlorinated water, dipping the spoons for delivery of vaccine in either bleaching powder or disinfectants and detergents, taking hot drinks just after vaccination, and injecting vaccine into cubes of desiccated semiporous sugar (which may well be full of enteropathogenic microbes) are well recognised. ${ }^{2}$ Obviously the final procedures may neutralise all the meticulous planning and care that might have been taken earlier to ensure vaccine of good quality.

It goes without saying that, apart from maintenance of a cold chain during transport of vaccines, only a check on the administration practices in vogue and delivery of an adequate quantum of each serotype to every vaccinee will ensure satisfactory seroconversion rates, as observed in certain areas. ${ }^{4}$ All who are concerned with poliomyelitis all over the globe should wake up to these realities of vaccine potency and the actual administration of vaccine, which alone will solve the problems of the so-called vaccine failures.

S C ARYA

New Delhi 110048

India

1 Anonymous. WHO Chronicle $1974 ; 28: 410-3$.

Arya SC, Sharma MID, Shrivastar JB, Ramachandran

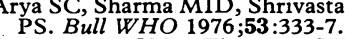

${ }^{3}$ Rasmussen CM, Thomas CW, Mulrooney RJ, Cabasso VJ, Nozell H, Ruegsegger JM, Cox HR. f Pediat 1966;68:199-203.

\section{Not so unusual seat-belt injuries}

SIR,-I read with approval the various leading articles which offer general support for the compulsory wearing of car seat belts. I feel, however, that the case might be more usefully presented if some specific advice were given on the design of seat belt most recommended, for clearly some must be superior to others.

On that note I write in support of the inertia-reel type of belt, for in the past 18 months I have treated three patients with serious injuries resulting from the use of the fixed variety of seat belt. Each of my patients sustained his injury while alighting from a stationary car: each unwittingly placed one foot in a trailing loop of the seat belt, the entangling effect of which resulted in a heavy fall to the ground.

The first patient, a woman aged 61 years, sustained an external rotation, fracturedislocation of the right ankle. The second patient, a woman aged 63 years, sustained a comminuted fracture of the lower third of her left tibia and fibula. The third patient, a man 